\title{
UM ENSAIO SOBRE OS FUNDAMENTOS LIBERAIS-SOCIAIS DA CONSTITUIÇÃO BRASILEIRA DE 1988
}

\author{
AN ESSAY ON THE LIBERAL-SOCIAL FOUNDATIONS OF THE BRAZILIAN \\ CONSTITUTION OF 1988
}

\begin{abstract}
Alfredo Copetti Neto
Possui pós-doutorado na Universidade do Vale do Rio dos Sinos (UNISINOS/PDJ-CNPQ, 2014), doutorado em Teoria do Direito e da Democracia pela Università degli Studi Roma Tre (UNIROMATRE, 2010, Revalidado UFPR) e mestrado em Direito Público (Filosofia do Direito) pela Universidade do Vale do Rio dos Sinos (UNISINOS, 2006). Atualmente é editor da Revista do Instituto de Hermenêutica Jurídica (1678-1864), lider do grupo

Direitos Humanos, Relações Internacionais e Equidade e membro pesquisador do grupo

Estado e Constituição, ambos do Cnpq; professor Visitante na Universitá di Roma (La Sapienza), professor Permanente no mestrado em Direitos Humanos na Unijuí e professor Adjunto de Teoria do Direito da Universidade Estadual do Paraná (UNIOESTE).

E-mail: alfredocopetti@yahoo.com

Mariana da Silva Garcia

Mestre em Direitos Humanos pela Universidade Regional do Noroeste do Estado do Rio Grande do Sul (UNIJUÍ). E-mail: garciamarian@ hotmail.com
\end{abstract}

Recebido em: 03/02/2017

Aprovado em: 06/04/2017

Doi: $10.5585 /$ rdb.v18i7.593

RESUMO: No presente artigo, busca-se demonstrar que a defesa da constituição e do estado de direito tem uma finalidade não sua, interna, mas externa, com vista à nação, que desloca a preocupação do constituinte para um projeto de desenvolvimento social e econômico. Identificase que a Constituição Federal de 1988, a partir do postulado da legalidade material, da separação e divisão dos poderes, da garantia de direitos individuais e sociais, institui mecanismos que impedem ou obstaculizam o abuso e o exercício arbitrário e ilegítimo do poder e da previsão de deveres de atuação do Estado na esfera econômica, a fim de que sejam observados os princípios consagrados na ordem econômica. A importância do estudo se justifica, na medida em que se a discussão acerca dos fundamentos filosófico-políticos da Constituição Brasileira não ocorrer de forma séria, permanecerá o tradicional dilema que envolve o debate acerca do conceito de constituição econômica e, acompanhando transversalmente essa confusão, estarão as contemporâneas posições políticas adotadas acerca das liberdades civis, que minam e desvirtuam os fundamentos republicanos e laicos do estado e do direito.

Palavras-chave: Constitucionalismo. Liberalismo social. Princípio da legalidade. Separação dos Poderes. Direitos Individuais. 
ABSTRACT: In this article, it is sought to show that the defense of the constitution and the rule of law has a purpose that is not internal, but external, for the sake of the nation, which shifts the concern of the constituent for a social and economic development project. Taking into account the postulate of the substantive legality, the separation and division of powers, and the individual and social rights guarantees, it is found that the Federal Constitution of 1988 establishes mechanisms that prevent or hinder the abuse and arbitrary and illegitimate exercise of power, forecasting the duties of State performance in the economic sphere, so that the principles of the economic order are observed. The importance of this study justifies itself, in a way that if the discussion about the philosophical and political foundations of the Brazilian Constitution does not occur in a serious way, the traditional dilemma surrounding the debate about the concept of economic constitution will persist. Transversely following this confusion, it will be found the contemporary politic positions adopted on civil liberties, that undermine and distort the republican and laic foundations of the state and the Law.

Keywords: Constitutionalism. Social liberalism. Principle of legality. Separation of Powers. Individual rights.

SUMÁRIO: Introdução; 1. A liberdade, o liberalismo social e sua adequação ao Constitucionalismo Contemporâneo; 2. Uma análise dos postulados liberais-sociais na Constituição Brasileira de 1988; Conclusão; Referências Bibliográficas.

\section{INTRODUÇÃO}

Para, em alguma medida, ser compreendido o conceito atual de constituição é necessário partir de uma premissa, que é aquela delineada por Konrad Hesse (1991) no ensaio “A força normativa da constituição". Hesse, contrapondo Lassalle, em 1959, em sua aula inaugural na Universidade de Freiburg-RFA, defendeu a ideia segundo a qual a constituição, mesmo no embate em relação aos fatores reais de poder, não deveria ser considerada a parte mais fraca da contenda. Segundo o autor alemão, a constituição é dotada de uma força autônoma, que age na determinação e na estabilização da vida do Estado. Ele asseverou que a constituição normativa e jurídica- tem na sua lógica a imposição de tarefas cuja realização faz com que ela se torne força ativa, o que depende, sobremaneira, não só da vontade de poder, mas especialmente, da vontade de constituição (HESSE, 1991, p. 9).

Pode-se afirmar, por conta disso, que Hesse, ao lado de outro autor daquela época, Vezio Crisafulli (1952), responsável por cunhar o termo normas programáticas ${ }^{l}$ - tão caro ao constitucionalismo Brasileiro pós 1988 -, bem como, contemporaneamente, de J. J. Gomes Canotilho (2001), autor da obra Constituição Dirigente e Vinculação do Legislador pretenderam, cada qual ao seu modo, estabelecer as arestas para aquilo que se pode nominar de defesa da constituição e do estado de direito.

Nessa perspectiva, a Constituição Brasileira de 1988 estabelece uma profunda ligação com o constitucionalismo erigido no Segundo Pós-Guerra. Com a intenção de defender-se de possíveis ataques políticos (despóticos), econômicos (de poder) e morais (reacionários/não laicos) a Constituição avoca em seu texto a ideia radical de rigidez constitucional e de controle de constitucionalidade material, além do já consagrado princípio da limitação do poder estatal - a

\footnotetext{
1 Sobre o termo "normas programáticas" no Brasil ver: SILVA, José Afonso da.A aplicabilidade das normas constitucionais. São Paulo: Malheiros, 1999. Em relação à utilização equivocada do termo cunhado por Crisafulli no Brasil, ver, por todos: BERCOVICI, Gilberto. Ainda faz sentido a Constituição Dirigente? In: Revista do Instituto de Hermenêutica Jurídica n. VI "20 anos de constitucionalismo democrático: e agora?” IHJ, 2008.
} 
partir da exigência de respeito ao princípio da legalidade e da separação dos poderes - aliado à garantia de direitos individuais e sociais ${ }^{2}$.

Por conta disso, pretende-se demonstrar, com o presente ensaio, que a defesa da constituição e do estado de direito tem uma finalidade não sua, interna, mas externa, com vista à nação, que desloca a preocupação do constituinte para um projeto de desenvolvimento social e econômico, voltado à melhoria das condições sociais de vida da maioria da população (BERCOVICI, 2005, p. 9).

Em outros termos, a esfera pública passa a ter um papel ativo na garantia de direitos e na efetivação de uma justiça social, o que, segundo Bercovici, pode ser a última possibilidade que temos para a construção de um Estado nacional republicano e democrático (BERCOVICI, 2005, p.10).

Esse compromisso constitucional - que se expressa na ideia política progressista e social, recriada/avançada do liberalismo clássico, e que juridicamente se arranja no texto constitucional pela importância da pessoa humana; pela compressão da igualdade jurídica entre os indivíduos; pela soberania popular que contratualmente cria o Estado - ideologicamente se funda na concepção de liberalismo social ${ }^{3}$.

Por outro lado, se a discussão acerca dos fundamentos filosófico-políticos da Constituição Brasileira não ocorrer de forma séria, em primeiro lugar, permanecerá o tradicional dilema que envolve o debate acerca do conceito de constituição econômica; depois, acompanhando transversalmente essa primeira confusão, estarão as contemporâneas posições políticas adotadas acerca das liberdades civis, que minam e desvirtuam os fundamentos republicanos e laicos do estado e do direito.

\section{A LIBERDADE, O LIBERALISMO SOCIAL E SUA ADEQUAÇÃO AO CONSTITUCIONALISMO CONTEMPORÂNEO}

O liberalismo social surge como um passo adiante - e muito mais qualificado - da doutrina liberal clássica, razão pela qual, em alguma medida, não há como estabelecer um conceito de liberalismo social que não abarque elementos do próprio liberalismo como doutrina política e do Iluminismo como movimento filosófico, este último mesmo numa perspectiva crítica.

Não obstante isso, para que seja possível apresentar uma compreensão adequada do liberalismo, é necessário tratar - ainda que brevemente - da questão que envolve o termo liberdade, na perspectiva em que a história do liberalismo, em suas diversas manifestações, conta também, de algum modo, a história da liberdade ${ }^{4}$.

Nesse sentido, importante são as colocações do italiano Nicola Abbagnano (2008), que em seu Dizionario di Filosofia atribui ao termo liberdade três significados fundamentais, cuja complexa estrutura ocorre por conta de seu viés histórico-filosófico, e se compõem do seguinte

\footnotetext{
${ }^{2}$ Ferrajoli (2013) classifica o constitucionalismo brasileiro como não meramente rígido, mas rigidíssimo, por conta da existência de cláusulas pétreas no texto constitucional, bem como pela ampla gama de garantias, oriundas das ações constitucionais. Ainda, o autor italiano refere como novidade do constitucionalismo brasileiro, o duplo controle de constitucionalidade e a função ampliada de garantia do Ministério Público. (FERRAJOLI, 2013).

${ }^{3}$ Embora haja inúmeras expressões para definir uma concepção liberal social, opta-se pelo termo liberalismo social que utilizando expressões de natureza econômica, deixa clara a relação com as questões de direitos sociais. Ainda, ao usar a expressão liberalismo social demonstra-se a vinculação a teóricos como Leonard Hobhouse - que utiliza o termo social liberalism - e a toda tradição inglesa, que desde Stuart Mill tem se preocupado com a repartição justa da produção e com a eliminação dos privilégios decorrentes do nascimento. Para tanto, ver: HOBHOUSE, Leonard. Liberalism. London: Oxford University Press, 2009.

${ }^{4}$ Sabe-se que o discurso acerca da liberdade traz posições antagônicas, contraditórias. Em nome da liberdade houve - e há - exclusão e opressão. Por conta disso, não se está a tratar especificamente do Estado Liberal, mas dos pressupostos que o erigiram - e que em alguma medida foram esquecidos - sob o amálgama da liberdade.
}

Revista de Direito Brasileira | São Paulo, SP | v. 18 | n. 7 | p. 134 - 148 | Set./Dez. 2017 
modo: a) liberdade como ausência de limite, conformada a partir da autodeterminação e da autocausalidade; b) liberdade vinculada não ao indivíduo, mas ao todo (ao Estado, por exemplo) como necessidade. Conduzida a partir da primeira percepção (autodeterminação), mas dela distante, pois pautada no âmbito da totalidade; c) liberdade como possibilidade ou escolha, portanto finita, condicionada.

Ainda, pondera Abbagnano, independentemente da forma assumida pela liberdade nos mais variados campos do conhecimento (liberdade moral, liberdade política, liberdade econômica, etc.) ela, necessariamente, orbitará o léxico dos três conceitos acima delineados. Especificamente, compreende-se adequado tratar a liberdade, em relação ao modelo constitucional brasileiro, pelo terceiro viés proposto, ou seja, "come misura di possibilità, quindi scelta motivata o condizionata" (2008, p. 638), afastando-se tanto de uma autodeterminação identificada consigo mesma, como de uma identidade absoluta que age como causa individual.

$\mathrm{O}$ fato de o indivíduo assumir a autoria de suas próprias escolhas, por um lado, e deixar ausente de responsabilidade a divindade, por outro, compreendendo a causalidade limitada de forma objetiva por conta dos modelos de vida disponíveis, faz com que a liberdade se desloque para o âmbito da finitude, de um projeto concreto a ser desenvolvido. A admissão da determinação do homem em relação às suas condições, sem que haja uma previsão infalível acerca das suas escolhas, enaltece a liberdade de fazer, promovida pelos contratualistas, em especial Hobbes e Locke, em contraste com a liberdade de querer, consolidada pelo pensamento medieval como livre arbítrio. Para Locke, por exemplo, a liberdade, em uma perspectiva natural, ocorre na medida em que nenhum indivíduo esteja vinculado a qualquer poder superior; numa perspectiva social, a liberdade consiste em submeter-se somente à lei estabelecida pelo consenso (ABBAGNANO, 2008).

A partir das perspectivas mais socializantes, para além de seus fundamentos naturais, o termo liberdade assume um papel limitador. Para Stuart Mill (1962) a liberdade deve ser concebida como limite ao poder que a sociedade legitimamente exerce sobre o indivíduo. Na obra "Sobre a Liberdade", Mill traça uma evolução desse limite desde os governos despóticos, nos quais se identifica um antagonismo entre o governante e o povo por ele governado consubstanciando-se a liberdade em uma proteção contra a tirania dos governantes, até os governos "democráticos", nos quais não haveria receio da tirania e seria desnecessária a limitação ao exercício do poder uma vez que o interesse e a vontade do governante são o interesse e a vontade da nação. A ideia de que o povo não precisaria limitar - mas somente compartilhar - seu poder sobre si mesmo é desconstituída por Mill (1962, p. 41, tradução nossa) que considera que "o povo que exerce o poder não é sempre o mesmo povo sobre quem o poder é exercido" 5 , dessa forma a vontade do povo significa a vontade da mais ativa e numerosa parte do povo, ou seja, da "maioria"6, justificando-se a limitação do poder a fim de evitar a opressão do "povo" contra uma parte de "si mesmo".

Nesse ponto, Mill considera necessária a intervenção reguladora do Estado, superando a ideia do liberalismo clássico, de cunho estritamente individualista, desde que atenda a única justificativa existente para interferência dos homens na liberdade de ação do outro: a autoproteção. De acordo com Mill (1962, p. 50, tradução nossa) "a única razão legítima para se usar a força contra algum membro de uma comunidade civilizada é impedir que cause dano a outros"7. Nesse contexto, nenhum indivíduo pode ser obrigado a fazer ou deixar de fazer algo sob a justificativa de que desse fazer (ou não fazer) deriva um benefício para si, pois para Mill a única parte da conduta que o indivíduo pode responder perante a sociedade é aquela que concerne

\footnotetext{
${ }^{5}$ Texto original: "[...] el Pueblo que ejerce el poder no es siempre el mismo pueblo sobre el que se ejerce”. (MILL, 1962, p. 41).

${ }^{6}$ Uma maioria que, quando se trata do Brasil, especificamente, vem representada por uma elite muito bem definida.

${ }^{7}$ Texto original: "[...] la única razón legítima para usar de la fuerza contra um membro de uma comunidade civilizada es la de impedirle prejudicar a otros". (MILL, 1962, p. 50).
}

Revista de Direito Brasileira | São Paulo, SP | v. 18 | n. 7 | p. 134 - 148 |Set./Dez. 2017 
aos outros. "Na parte que diz respeito a si próprio, a sua independência é, de fato, absoluta. Sobre si mesmo, sobre seu corpo e seu espírito, o indivíduo é soberano" (MILL, 1962, p. 10, tradução nossa) ${ }^{8}$.

Em tal perspectiva é que se desenvolve a liberdade política, e é a partir dela, também, que se aloca o problema fundamental da Liberdade, que é o problema quanto a sua medida: a medida de participação individual e coletiva no controle das leis e a medida que tais leis têm em limitar-lhes a capacidade de escolha. Eis o dilema da liberdade e, por consequência, o dilema que se estabeleceu ao redor do liberalismo moderno.

A dificuldade que há em estabelecer uma "medida" para a liberdade atinge de forma inevitável o próprio liberalismo e por consequência a estrutura do direito e da constituição como projeto. Ainda assim, estabelecer elementos que auxiliem na compreensão de que liberdade se está a falar é importante, uma vez que o liberalismo, embora não forme um conjunto homogêneo de ideias, em alguma medida, apresenta-se como uma narrativa ao desenvolvimento e à manutenção da liberdade.

Segundo Nicola Mateucci (2010), parte da dificuldade em se conceituar o termo está relacionada ao fato de a história do liberalismo estar muito ligada a própria história da democracia, tornando árdua a tarefa de distinguir o que existe de liberal e o que existe de democrático nas atuais democracias liberais. Além disso, como liberalismo surge em diferentes países e em diferentes momentos históricos diferentes é árdua a tarefa de identificar o que há de comum nesse "movimento liberal", a fim de estabelecer uma definição de liberalismo que contemple esses diversos cenários.

Ao abordar o surgimento do liberalismo, Leonard Hobhouse (2009) afirma que se o Estado Moderno inicia a partir de uma ordem autoritária, é o protesto contra essa ordem instituída - protesto religioso, político, econômico, social e ético - que dá início à história do liberalismo.

$\mathrm{Na}$ busca de elementos que identifiquem o liberalismo, Mateucci (2010) considera que a defesa do Estado Liberal, entendido como um estado que garante os direitos do indivíduo contra o poder político e, que para tal, exige formas, mais ou menos amplas, de representação política, é um elemento presente em todo o pensamento liberal.

Todavia, a questão é bem mais complexa, pois, a partir das pautas trazidas pelo socialismo, o liberalismo passa a enfrentar o seu maior desafio: conciliar a liberdade econômica com a justiça social. Até então, o liberalismo, na sua manifestação clássica, lutava pelas liberdades de religião, de participação no poder político, de iniciativa econômica, reivindicando a não intervenção do Estado e a garantia desses direitos individuais, civis e políticos. Para que fosse possível trazer soluções para a questão social, o liberalismo precisou renunciar a defesa da não intervenção do estado na vida econômica 9 .

John Stuart Mill é apontado como o primeiro entre os teóricos do liberalismo a ressaltar instâncias trazidas pelo socialismo para a concepção liberal de Estado. Dentre os pontos elencados por Mill, destaca-se a preocupação com a repartição justa da produção e a eliminação

\footnotetext{
${ }^{8}$ Texto original: "Para aquello que no le atañe más que a él, su independência es, de hecho, absoluta. Sobre sí mismo, sobre su cuerpo y su espíritu, el individuo es soberano".(MILL, 1962, p. 10).

${ }^{9}$ MYDRAL (1960) esclarece a diferença entre planejamento econômico e intervenção estatal, na medida em que o planejamento é a alternativa mais liberal - e é a resposta- para o caos criado pela intervenção sempre existente e desordenada do estado na economia. Obviamente que, nesse ensaio, nos valemos do termo intervenção para expor a perspectiva socializante que assume a função da esfera pública. Para essa perspectiva ver, ainda, Venâncio Filho (1968, p. 6 et seq.). Para que seja compreendida a intervenção no âmbito jurídico e constitucional, ver os autores Albino de Souza (2002, p. 13 et seq.) e Eros Grau (2008, p. 64) que considera que "o capitalismo se transforma, na medida em que assume um novo caráter social". Também importante a contribuição de Cabral de Moncada (2007, p. 9), que entende que "para a compreensão acabada dos fins da intervenção é necessário um aviso plena e integrada dos meio econômico mas também social em que vivemos esbatendo fronteiras entre diversos níveis de actividade". Ainda, ver o artigo dos autores Copetti Neto e Cattoni de Oliveira (2013b) intitulado "Entre direito, economia e política - as contribuições da ciência do estado alemã (Staatswissenchaft) para o surgimento no século XIX de uma nova ciência do direito".
} 
dos privilégios decorrentes do nascimento. Para Nicola Tranfagalia, "enfatizando com clareza a distinção entre ciência e política econômica, Mill foi, sem dúvida, o precursor da intuição fundamental da ideologia liberal-socialista” (BOBBIO; MATTEUCCI, 2010, p. 705).

Entretanto, é a partir da metade do século XIX que o liberal-socialismo melhor se define como doutrina e "desperta interesse e consenso crescentes junto a minorias intelectuais em toda a Europa". A crise do marxismo e as discussões teóricas promovidas à época fazem com que os socialistas passem a rever princípios da doutrina marxista ortodoxa a fim de concilia-los com a realidade da sociedade capitalista. Na mesma medida, o desenvolvimento da indústria e a evolução do movimento operário evidencia as limitações da ideologia liberal, que parece "incapaz de resistir [...] a mensagem marxista, empenhada em proclamar com ardor a necessidade de justiça social para as massas proletárias". De acordo com Nicola Tranfagalia é a partir daí que passamos a identificar "tentativas de síntese entre socialismo e liberalismo, enfatizando ora um ora outro termo do binômio" (BOBBIO; MATTEUCCI, 2010, p. 706) ${ }^{10}$.

Importante referir que, embora seja possível apontar diversos movimentos e correntes com ideias e motivações liberal-socialistas, define-se o núcleo da ideologia liberal-socialista a partir de referências dos teóricos que trataram especialmente do Liberal-socialismo ou socialismo liberal.

Nesse contexto, o primeiro autor a ser lembrado é Thomas Hill Green (1986), que afirma que as questões que envolvem educação, habitação, e condições sociais em geral devem ser preocupação de todos. Apesar do autor apoiar o ideal liberal de que o indivíduo é autônomo e de que o Estado não pode forjar o caráter moral de um indivíduo, Green considera que o governo tem um papel legítimo e necessário de moldar as condições políticas, sociais e econômicas gerais em que indivíduos estão situados. Dessa forma, caberá ao Estado enfrentar circunstâncias sociais e econômicas, mas as relações entre as pessoas devem ser regidas sob o prisma do individualismo. Assim, dentro de uma concepção liberal, Green afirma que é papel do Estado criar e assegurar as condições sociais, políticas e económicas em que os indivíduos possam desenvolver as suas capacidades latentes em toda a extensão possível.

Ainda assim, embora Green tenha dado ao liberalismo "um recomeço de vida conjugando os valores básicos dos direitos e liberdades individuais com uma nova ênfase na igualdade de oportunidades, e no ethos de comunidade" (MERQUIOR, 1991, p. 154), não chegou a conferir ao "novo liberalismo" uma inflexão socialista.

José Guilherme Merquior (1991) considera que o liberalismo social floresceu nos primeiros anos do século XX, destacando a contribuição de Leonard Trelawny Hobhouse. Hobhouse (2009) apresenta uma concepção de liberalismo que abarca também as "liberdades sociais", considerando que a luta pela liberdade está relacionada com a luta pela igualdade. O autor aborda o liberalismo a partir da experiência industrial da Inglaterra, entendendo que são necessárias algumas medidas de regulação, em especial no que tange as questões relacionadas ao trabalho (HOBHOUSE, 2009, p. 34) ${ }^{11}$.

Ainda, a partir da análise do contexto europeu, Hobhouse afirma que a organização hierárquica da sociedade restringia certos trabalhos e ocupações, na medida em que não assegurava oportunidade de educação para os indivíduos de uma determinada "categoria ou classe". Diante disso, considera que a luta pela liberdade tão relevante para o liberalismo envolve também uma luta pela igualdade, pois só é possível afirmar que há uma efetiva liberdade de

\footnotetext{
${ }^{10}$ Ver também: COPETTI NETO e CATTONI de OLIVEIRA (2013b).

${ }^{11}$ Exemplo disso é a questão atinente a liberdade de associação, defendida pelos liberais e tratada por Hobhouse. De acordo com o autor (2009, p. 40), os poderes de uma associação são diferentes dos poderes dos indivíduos e algumas associações podem se tornar tão poderosas que formam um Estado dentro de um Estado. Nesses casos, se a associação age de forma a oprimir os outros ou até mesmo os seus próprios membros qual a função do liberalismo: proteger o indivíduo contra o poder da associação ou proteger o direito de associação contra toda e qualquer restrição legal?.
} 
escolher e seguir uma ocupação se é assegurado aos indivíduos iguais oportunidades para seguir essa atividade.

É importante identificar que o objetivo da promoção de direitos - que proporcionasse aos membros da sociedade uma igualdade viva de direitos - é o autodesenvolvimento individual. Assim, "os direitos hobhousianos são concedidos pela sociedade, mas sua função reside em auxiliar o crescimento da individualidade" (MERQUIOR, 1991, p. 163).

Nesse contexto, é possível afirmar que Hobhouse (2009) aprofunda o debate acerca do pensamento liberal social e, da mesma forma que Green (1986) considera que medidas de regulação são por vezes necessárias e que o Estado deve assegurar as condições sociais, políticas e econômicas em que os indivíduos possam desenvolver plenamente as suas capacidades ${ }^{12}$.

Embora a incorporação da igualdade como um princípio de atuação política sirva para a efetivação da liberdade como escolha e apareça como submissão de condutas individuais para a concretização de objetivos mais amplos, determinados, não há de se pressupor uma restrição lato senso ao termo liberdade. Na verdade, o que há é uma qualificação da liberdade, por um lado; e uma extensão, por outro. Ambos os lados, de qualificação e de extensão, atuam para proporcionar um mínimo de condições sociais e econômicas para que o indivíduo desfrute da própria liberdade. Mais do que tudo: o raciocínio que se atinge por essa perspectiva é a centelha inicial do que posteriormente foi muito bem desenvolvido por Amartya Sen (2006, p. 356 et seq.) no que tange ao desenvolvimento das capacidades fundamentais dos indivíduos, pois é evidente que uma esfera pública que vise a proteger e estimular as capacidades fundamentais dos seres humanos, em direção à sua igualdade, tenha maior possibilidade de expansão da liberdade e, inclusive, da própria atividade econômica (SEN, 2005, 2006).

Exemplo privilegiado dessa nova visão encontra-se historicamente na denominada American Progressive Era, em que o direito americano também enfrentou a dicotomia individual(ismo)-social(ismo), tendo o pensamento jurídico progressista (fundado no realismo jurídico) defendido uma distribuição mais igualitária da riqueza e o fortalecimento do bem-estar social. Levando em conta o papel transformador do direito, os progressistas passaram a sustentar que essa função seria melhor desenvolvida a partir da relação entre direito e economia, ciência capaz de fortalecer a promoção da redistribuição da riqueza na sociedade (COPETTI NETO, 2012).

A proposta político-jurídica do Pós-Guerra veio consolidar e ideia segundo a qual há uma manifestação intrínseca de poder no âmbito privado, para além da mera manifestação pública do poder. Nesse sentido, a força do caráter rígido e prescritivo das constituições contemporâneas, que eleva o direito a um patamar limitador e vinculante, reestrutura o léxico no qual se enquadra o direito de liberdade, ou seja, o desvincula tanto da esfera da autodeterminação política pública, quanto da esfera da não-constrição à decisão econômica privada e o eleva, juntamente aos direitos sociais, a um patamar delimitador, seja à própria autodeterminação política, seja à decisão econômica(COPETTI NETO, 2013a).

Essa busca jurídica de uma equalização econômica mostra-se aparentemente inconciliável com a tradição do pensamento liberal, explicando assim a contraposição histórica entre liberalismo e democracia, na medida em que há divergências no que tange ao alcance da igualdade promovida pelo direito (BOBBIO, 2000).

Entretanto, Bobbio (2000, p. 21), um dos grandes nomes à consolidação do liberalismo social na Europa, sustentou que "não só o liberalismo é compatível com a democracia, mas a democracia pode ser considerada como o natural desenvolvimento do Estado liberal". A superação dessa divergência, que possibilita hoje usarmos a expressão "liberal-democracia", passa pela visão da democracia não apenas pelo seu ideal igualitário, mas a partir de sua proposta política de preponderância da soberania popular e da garantia de direitos.

12 É também em razão desses argumentos que Hobshouse (2009) sustenta que o liberalismo apoia um sistema nacional de educação gratuita.

Revista de Direito Brasileira | São Paulo, SP | v. 18 | n. 7 | p. 134 - 148 | Set./Dez. 2017 
Nesse ponto, é possível perceber uma aproximação do liberalismo à democracia, e é possível defender que não somente o método democrático é necessário para a salvaguarda dos direitos fundamentais da pessoa, mas o conteúdo e a garantia desses direitos são extremamente necessários para o correto funcionamento do método democrático (COPETTI NETO, in press).

Nesse sentido, para o pleno desenvolvimento dos direitos de liberdade foi necessário destacar a relevância, a complementariedade e a convergência que se estabelece entre estes e os direitos sociais, fruto das lutas pela igualdade jurídico-material que evidenciaram a premissa segundo a qual ninguém é livre sem as mínimas condições materiais de sobrevivência: à previdência social, ao trabalho, à saúde e à instrução. Para que fosse possível o cumprimento dessa tarefa, portanto, erigiu-se uma complexa estrutura jurídica que foi concebida como Estado Constitucional de Direito, cujas características se fundaram em um duplo aspecto: no controle material de constitucionalidade e na rigidez constitucional.

\section{UMA ANÁliSE DOS POSTULADOS LIBERAIS-SOCIAIS NA CONSTITUIÇÃO BRASILEIRA DE 1988}

Especificamente, no constitucionalismo brasileiro, conforme leciona Bonavides (2008, p. 366), há a forte influência do modelo de weimariano ${ }^{13}$ a partir da Constituição de 1934, que produz uma mudança substancial de orientação e passa a consagrar "um pensamento diferente em matéria de direitos fundamentais da pessoa humana, a saber, faziam ressaltar o aspecto social, sem dúvida, grandemente descurado pelas Constituições precedentes".

A Constituição Federal traz em seu texto postulados que tem íntima relação com os fundamentos do liberalismo social e que implicam mudanças: seja no âmbito da teoria do direito (e da constituição), seja no âmbito das instituições jurídico-políticas, seja na perspectiva da aplicação/interpretação do texto constitucional à efetivação de regras e de princípios. É possível identificar, sobremodo, elementos do liberalismo social desde os primeiros dispositivos constitucionais que estabelecem os fundamentos e os objetivos da República, na linha que perpassa os direitos e as garantias individuais e coletivos, bem como no acento colocado à ordem econômica pela constituição econômica (MOREIRA, 2002, p. 5).

A compreensão dessa perspectiva aparece já no Título I da Constituição Brasileira de 1988, onde são determinados os Princípios Fundamentais da República (desde o art. $1^{\circ}$ até o art. $4^{\circ}$ ). O art. $1^{\circ}$ caput é o responsável por expor a tríade elementar da nação, a sua porta de entrada, a partir dos princípios: Republicano, Federativo e da implicação do referencial democrático ao estado de direito, o Estado Democrático de Direito. Trata-se, por um lado, expressamente de "um comando objetivo aplicável e exigível a toda aplicação do sistema normativo brasileiro, constitucional e infraconstitucional" (BARRETO LIMA, 2013, p. 108); por outro, de uma proposta que visa efetivamente à transformação da realidade, à mudança do status quo que, para tanto, "instaura uma sociedade coesa e integrada, sem romper com a autonomia individual própria da tradição liberal, porém voltada à transformação das condições de vida dos cidadãos (STRECK, 2013, p. 113)”.

Não por outra razão que os fundamentos propriamente ditos da República vão ao encontro da tríade estabelecida acima, e são determinados pelos incisos específicos do art. $1^{\circ}$. Eles apontam para questões oriundas do constitucionalismo do Pós-Guerra e alocam subterfúgios

\footnotetext{
${ }^{13}$ A Constituição Alemã de 1919 se destaca especialmente pelo Livro II que estabeleceu os Direitos e Deveres fundamentais do cidadão alemão que traz um rol sistematizado de direitos com o objetivo de garantir tanto liberdades públicas como prerrogativas de índole social. Para Bercovici, a Contituição de Weimar a tem por fundamento a busca de um compromisso em uma estrutura política pluralista, trazendo para o debate "a questão da instauração de uma democracia de massas, ou seja, de uma democracia que deveria ser entendida na forma e na substância, pois importava na emancipação política completa e na igualdade de direitos, incorporando os trabalhadores ao Estado pluralista". (BERCOVICI, 2011b, p. 571).
} 
ousados e qualificados ao (re)enraizamento republicano e democrático. A Dignidade da Pessoa Humana, "que representa uma norma jurídico-positiva dotada, em sua plenitude, de status constitucional formal e material" (SARLET, 2013, p. 108); os Valores Sociais do Trabalho, como fundamento revigorado da estrutura constitucional, a pari passo com a Constituição Italiana de 1948, efetivamente consolidado como opção constituinte de privilegiar o trabalho como condição integrante e nuclear de um novo paradigma jurídico; os Valores da LivreIniciativa $^{14}$, um dos elementos que apregoam o modo de produção capitalista, mas que em relação aos dois princípios basilares antecedentes vem harmonizado e que, por conta disso, exacerba o papel mediador da esfera pública nesta relação ${ }^{15}$.

Não obstante isso, há a necessidade de ser ressaltado o papel do Estado (Promoção e Proteção) e do interprete, obviamente, à efetivação dos princípios fundamentais acima mencionados, pois a perspectiva anunciada no primeiro artigo da Constituição Brasileira é a de projetar uma sociedade em que todas as manifestações de iniciativa e de trabalho humanos mesmo de carris não econômico - sejam compreendidas como valores sociais, para além da mera individualidade ${ }^{16}$.

Esse projeto se enaltece ainda mais por conta do art. $3^{\circ}$ da Constituição de 1988 , em que os objetivos da república são definidos e que, também por isso, traz à tona a tese do dirigismo constitucional, proveniente de Portugal ${ }^{17}$. Embora calcado na proposta portuguesa, o dirigismo compromissário brasileiro não repercute o caráter revolucionário à transformação do modo de produção, rumo ao socialismo, que foi protagonizado pelos portugueses. O Brasil restringiu-se a optar por um novo modelo de estado (democrático de direito), em que no plano econômico há a especificidade do cuidado quanto à questão social (BOLZAN; STRECK, 2013, p. 148), que para tanto erigiu-se uma índole intervencionista, a fim de garantir o preenchimento do núcleo essencial daquilo que foi chamado de modernidade tardia não cumprida ${ }^{18}$.

Há um programa de ação e de legislação para o Estado brasileiro, que vincula todos os poderes (Executivo, Legislativo e Judiciário) e que estabelece uma ideologia constitucional a fim de promover o desenvolvimento nacional (BERCOVICI, 2005).

Especificamente, a diagramação dessa ideologia vem pormenorizada nos incisos do artigo $3^{\circ}$ da Constituição Brasileira, a partir de uma leitura contextualizada da situação social do país. Em outros termos, há um projeto jurídico-político a ser desenvolvido, ainda não alcançado, mas normativamente determinado que preconiza: a construção de uma sociedade livre, justa $e$ solidária; a garantia do desenvolvimento nacional; a erradicação da pobreza e da marginalização; a redução das desigualdades sociais e regionais; a promoção do bem de todos, sem preconceitos de origem, raça, sexo, cor, idade e quaisquer outras formas de discriminação".

O âmago constitucional, conforme Bercovici (2004, p. 102), vem posto segundo o critério de que "o Governo está vinculado à Constituição, não o contrário". Embora todas as dificuldades, há de se compreender que a Constituição Federal de 1988 "é um instrumento capaz de promover, por meio da atuação do Estado, a transformação social”.

Para tanto, o núcleo estruturante de direitos e garantias fundamentais elencado no Título II da Constituição Federal, a partir do artigo $5^{\circ}$ até o artigo 17, muito provavelmente seja um dos mais completos e profundos das novas constituições democráticas do Segundo Pós-Guerra, com base na Lei fundamental Alemã de 1949.

\footnotetext{
14 Ver: BERCOVICI, Gilberto. A iniciativa econômica na constituição brasileira de 1988. In: BOLZAN DE MORAIS, José Luis; COPETTI NETO, Alfredo. Estado e Constituição: estado social e poder econômico face a crise global. Florianópolis: Empório do Direito editora, 2015, p. 47 e sgts.

${ }^{15}$ Além da Soberania, da Cidadania e do Pluralismo Político.

${ }^{16}$ Para tanto ver: ADI 3512/ES, Rel. Min. Eros Grau, DJ, 23 jun. 2006.

${ }^{17}$ O termo Constituição Dirigente é cunhado em 1961 por Peter Lerche. Ver, para tanto, atigo intitulado Ainda faz sentido a Constituição Dirigente?de Gilberto Bercovici (2008).

${ }_{18}$ Para tanto, ver a tese acerca da teoria da constituição dirigente aplicada a países de modernidade tardia (TCDAPMT) desenvolvida por Lênio Streck na obra Jurisdição Constitucional e Decisão Jurídica (2013). Revista de Direito Brasileira | São Paulo, SP | v. 18 | n. 7 | p. 134 - 148 | Set./Dez. 2017
} 
Notadamente, por conta disso, o Título II da Constituição Brasileira vincula-se aos três elementos característicos substanciais contidos no texto: o conteúdo pluralista, o cunho dirigente e o caráter analítico. Direitos individuais e coletivos, sociais, de nacionalidade, direitos políticos e partidos políticos são ali abrangidos e assumem caráter de fundamentalidade, cuja relevância vem demostrada jurídico-hierarquicamente, sobretudo quanto à limitação do poder, tendo em vista sua força normativa suprema, que ativa o critério da aplicabilidade imediata dos direitos e garantias fundamentais, conforme determina o art. $5^{\circ} \S 1^{\circ}$ do texto.

Em que pese uma relativa falta de sistematização dos Direitos Fundamentais elencados na Constituição Brasileira de 1988, há que se considerar, por seu todo complexo, o cumprimento do critério elementar meta-jurídico da completude e da coerência lógica do texto, o que não obsta a compreensão da receptividade de novos conteúdos ampliativos de tais direitos.

No tocante aos direitos sociais, nesse prisma, além de assumirem no texto de 1988 capítulo próprio, no âmbito do art. 6 ao art. 11, eles também foram estendidos a outros elementos arraigados às necessidades existenciais humanas, tais como o direito à moradia, acrescentado ao art. $6^{\circ}$ pela Emenda Constitucional $\mathrm{n}^{\circ} 26$ de 2000, bem como o direito à alimentação inserido a partir da Emenda Constitucional no 64 de 2010.

Obviamente, há uma série de percalços acerca da efetivação dos direitos fundamentais, por conta da sua exacerbada judicialização, que tende a produzir efeito contrário à plena efetivação, bem como de uma crítica bastante eloquente acerca de sua analiticidade, para não dizer prolixidade, que visa a denunciar a hipertrofia normativa e o regresso ao mero simbolismo de determinados direitos fundamentais.

Não obstante isso, a Emenda Constitucional 45 de 2004, a fim de preservar a abrangência e efetivação de tais direitos, normatizou como direito fundamental, elencando no inciso LXXVIII do art. $5^{\circ}$, a razoável duração do processo e os meios que garantam a celeridade de sua tramitação e, ainda, expressamente garantiu, com os novos parágrafos $3^{\circ}$ e $4^{\circ}$, a equivalência à emenda constitucional dos tratados e convenções internacionais referentes a direitos humanos (por conta de votação qualificada no congresso nacional de 3/5), bem como a submissão do país à jurisdição do Tribunal Penal Internacional, à qual tenha aderido, respectivamente.

Se é verdade a afirmação segundo a qual há no âmbito das instituições do Estado uma espécie de abuso na limitação da ampla gama de direitos fundamentais, implícitos e expressos, elencados na constituição, também é verdade que o sistema de direitos fundamentais pátrios recebe, no próprio texto constitucional, uma série de ações de garantia, voltadas a dar suporte de ação aos entes individuais e coletivos, que buscam a jurisdição constitucional.

As ações constitucionais, Habeas Corpus, Habeas Data, Ação Popular, Mandado de Segurança Individual e Coletivo, bem como os mecanismos de controle de constitucionalidade abstrato, ampliados desde 1988, nos casos da ADPF e da ADC, dispostos na Constituição Brasileira, tendem a dar guarida horizontal e vertical a esta acentuada quantidade de direitos fundamentais, no âmbito individual e transindividual, como também promover a unidade e enrobustecer a força normativa da constituição.

A despeito disso, o princípio da legalidade, insculpido no art. $5^{\circ}$, II da Constituição Federal, evidencia a preocupação liberal clássica do legislador constituinte com o limite do poder estatal, estabelecendo que ninguém será obrigado a fazer ou deixar de fazer alguma coisa senão em virtude de lei. Nessa mesma perspectiva, estão a separação de poderes, e a liberdade religiosa, arraigada à laicidade do Estado a partir do art. 19, I, que veda à União, aos Estados, ao Distrito Federal e aos Municípios "estabelecer cultos religiosos ou igrejas, subvencioná-los, embaraçar-lhes o funcionamento ou manter com eles ou seus representantes relações de dependência ou aliança [...]".

Importante referir que a expressa menção do texto constitucional ao princípio da legalidade, da separação dos poderes e da laicidade do Estado não é suficiente para determinar 
que o constituinte tenha adotado fundamentos liberais sociais. O liberalismo clássico já apontava para a necessária limitação do poder do Estado e já trazia a liberdade religiosa como essencial, porém sem apontar para a previsão de igualdade material em direitos.

Nesse sentido, o próprio art. $5^{\circ}$ resolve a questão acerca da igualdade, e estabelece, já em seu caput, que "todos são iguais perante a lei, sem distinção de qualquer natureza", e evidencia que a questão da justiça social passa a ser central no texto constitucional.

Porém, é com a diagramação da ordem econômica e financeira, no título VII do texto constitucional, que a ideia de constituição econômica, como constituição político-jurídica da economia, vem à tona e configura instrumentalmente uma esfera pública capaz de levar ao fim e ao cabo o projeto previamente delineado nos artigos $1^{\circ}$ e $3^{\circ}$. Assim, o art. 170, que dá início aos princípios gerais da atividade econômica, estabelece que a ordem econômica, fundada na valorização do trabalho humano e na livre iniciativa, tem por fim assegurar a todos existência digna, conforme os ditames da justiça social”.

Nesse sentido, o valor do trabalho e da livre iniciativa reaparecem, e a justiça social conjuga o peso da proposta, na medida em que o constituinte assume um compromisso com a aderência a essa determinada concepção de justiça, assim como o faz com uma determinada ordem de valores (SARLET, 2008).

Como se não bastasse, a Constituição Econômica especifica, ainda, os princípios que determinam o horizonte das atividades econômicas no país, muitos já previamente expressos, seja no título I (Princípios Fundamentais), seja no título II (Direitos e Garantias Fundamentais), tais como a função social da propriedade e da redução das desigualdades regionais e sociais, evidenciando a preocupação com a questão social.

É justamente no âmbito da ordem econômica que residem as maiores divergências no que tange a qual o modelo político adotado pela Constituição Federal. Nesse ponto, há quem defenda que ao consagrar a livre iniciativa, a livre concorrência e a propriedade privada a Constituição Federal evidencia uma vinculação do liberalismo - na sua versão clássica - levando a um necessário afastamento do Estado do cenário econômico (FERREIRA FILHO, 1995). Nitidamente não há como prosperar tal defesa, e aí reside a ampla incompreensão filosóficopolítica do texto constitucional brasileiro, especificamente, e do liberalismo social, de modo amplo.

É inevitável relembrar que quando a Constituição Federal traz no art. $1^{\circ} \mathrm{o}$ valor social da livre inciativa como um dos fundamentos do Estado, e o repete no art. 170 a fim de estabelecer os princípios gerais da atividade econômica, ela determina, por um lado, uma liberdade jurídica, portanto limitada; por outro, ela faz questão de vincular a livre iniciativa a uma qualificação, ou seja, ao seu valor social, para além do mero individualismo. Para Bercovici (2011a, p. 263), nesses termos, "a previsão do valor social da livre iniciativa como fundamento da ordem econômica constitucional significa que a livre iniciativa não é garantida em termos absolutos", mas como uma atividade que contribui para o progresso da sociedade.

Dessa forma, ao incluir a expressão "valor social" afasta-se de uma perspectiva individualista e vincula-se a uma utilidade social, devendo satisfazer os interesses econômicos gerais, "com preferência aos setores tradicionalmente em desvantagem [...] nos confrontos econômicos com grupos mais privilegiados" (BERCOVICI, 2011a, p. 264).

Preocupado em propor uma leitura adequada da política econômica assumida pela Constituição Federal, Bercovici (2011b, p. 575) afirma que a Constituição Brasileira consiste em "um plano de transformações sociais e do Estado, prevendo, em seu texto, as bases de um projeto nacional de desenvolvimento". Do ponto de vista econômico, considera-se que a Constituição Federal institui uma ordenação da atividade econômica (prevendo limites a liberdade econômica, como a livre concorrência, a função social da propriedade e a defesa do consumidor), se preocupa com a satisfação das necessidades sociais e estabelece a direção do processo econômico geral ao 
tratar do desenvolvimento (art. $3^{\circ}$, II), do pleno emprego (art. 170, VIII) e da distribuição de renda (art. $3^{\circ}$, III).

Nessa perspectiva, "o Estado não só pode como deve atuar na esfera econômica e social, legitimado por toda uma série de dispositivos constitucionais" (BERCOVICI, 2011a, p. 271). Para concretizar os planos de transformação traçados pela Constituição Federal faz-se necessário uma política deliberada de desenvolvimento, em que se garanta tanto o desenvolvimento econômico como o desenvolvimento social, dada sua interdependência. Dessa forma, a intervenção do Estado na economia não atenta contra o liberalismo, pelo contrário, tem como pressuposto a visão liberal da existência de um dualismo entre o Estado e a sociedade (BERCOVICI, 2011b).

\section{CONCLUSÃO}

Partindo da concepção de Estado de Direito proposta pelo liberalismo social - que além da clássica subordinação do governo dos homens ao governo das leis, consubstanciada no princípio da legalidade, exige a positivação de direitos "fundamentais", entre eles os direitos sociais - os mecanismos constitucionais que impedem ou obstaculizam o abuso e o exercício arbitrário e ilegítimo do poder passam a ser indissociáveis do próprio Estado. Dessa forma, é possível afirmar que há na Constituição Federal diversos postulados de origem liberal social que permitem vincular a ideologia presente no texto ao liberalismo social.

Assim, se por um lado a constitucionalização dos direitos sociais representa um compromisso com a questão da justiça social; por outro, é necessário elencar alguns elementos essenciais para a definição e para a adequação jurídica da proposta, como, por exemplo: o respeito material à lei, consubstanciado na igualdade produzida pela proteção à diferença; a separação de poderes e a divisão de funções, enraizados na constante preocupação com a limitação do poder estatal e dos poderes privados; a garantia dos direitos individuais e coletivos, considerando que a igualdade jurídico-material passa a ser condição para a liberdade, e daí a importância de assegurar direitos sociais; a existência de mecanismos de proteção dos direitos constitucionalmente estipulados, por meio de medidas garantistas como, por exemplo, a jurisdição constitucional ${ }^{19}$ e a intervenção da esfera pública no domínio econômico, a fim de concretizar a regulamentação da economia e cumprir seu fim social nos moldes do dirigismo constitucional.

Nesse contexto, é de extrema relevância o papel determinado às instituições democráticas no conceito atual de constituição e, considerando a força normativa da Constituição Federal, não se pode mais aceitar a violação aos postulados trazidos pelas lutas sociais frente ao sistema constitucional de garantias.

\section{REFERÊNCIAS BIBLIOGRÁFICAS}

ABBAGNANO, Nicola. Dizionario di filosofia. 3. ed. aggiornata e ampliata. Torino: UTET Libreria, 2008.

ALBINO de SOUZA, Washington Peluso. Teoria da Constituição Econômica. Belo Horizonte: Del Rey, 2002.

\footnotetext{
${ }^{19}$ Sobre o papel da Jurisdição Constitucional ver a obra Jurisdição Constitucional e Decisão Jurídica de Lenio Streck
} (2013). 
BARRETO LIMA; Martônio Mont'Alverne. Comentário ao artigo 1º caput. In: CANOTILHO, J.J. Gomes; MENDES, Gilmar Ferreira; SARLET, Ingo Wolfgang. STRECK, Lenio Luiz. (Coords.) Comentários à Constituição do Brasil. São Paulo: Saraiva/Almedina, 2013.

BERCOVICI, Gilberto. A iniciativa econômica na constituição brasileira de 1988. In: BOLZAN DE MORAIS, José Luis; COPETTI NETO, Alfredo. Estado e Constituição: estado social e poder econômico face a crise global. Florianópolis: Empório do Direito editora, 2015.

BERCOVICI, Gilberto. Ainda faz sentido a Constituição Dirigente? In: Revista do Instituto de Hermenêutica Jurídica VI. Porto Alegre: IHJ, 2008.

BERCOVICI, Gilberto. Constituição econômica e desenvolvimento: uma leitura a partir da Constituição de 1988. São Paulo: Malheiros, 2005.

BERCOVICI, Gilberto. Dilemas da concretização da Constituição de 1988. In: Revista do Instituto de Hermenêutica Jurídica. Porto Alegre: IHJ, 2004.

BERCOVICI, Gilberto. Direito econômico do petróleo e dos recursos minerais. São Paulo: Quartier Latin, 2011a.

BERCOVICI, Gilberto. Política econômica e direito econômico. In: Pensar, Fortaleza, v. 16, n. 2, p. 562-588, jul./dez. 2011 b.

BERCOVICI, Gilberto; MASSONETTO, Luis Fernando. Limites da Regulação: esboço para uma crítica metodológica do novo "direito público da economia". In: Revista de Direito Público da Economia. n. 25, ano 7, 2009.

BOBBIO, Norberto; MATTEUCCI, Nicola; PASQUINO, Gianfranco. Dicionário de Política. Vol 2. $13^{\text {a }}$ ed. Brasília: Editora Universidade de Brasília, 2010.

BOBBIO, Norberto. A era dos direitos. Tradução Carlos Nelson Coutinho. Rio de Janeiro: Elsevier, 2004.

BOBBIO, Norberto. Liberalismo e Democracia. São Paulo: Brasiliense, 2000.

BOLZAN de MORAIS, José Luis; STRECK, Lenio Luiz. Comentário ao artigo $3^{\circ}$, caput. In: CANOTILHO, J.J. Gomes; MENDES, Gilmar Ferreira; SARLET, Ingo Wolfgang. STRECK, Lenio Luiz. (Coords.) Comentários à Constituição do Brasil. São Paulo: Saraiva/Almedina, 2013.

BONAVIDES, Paulo. Curso de Direito Constitucional. 23. ed. rev. atual. São Paulo: Malheiros, 2008.

CABRAL DE MONCADA, Luis S. Direito Econômico. 5.ed. Coimbra: Coimbra Editora, 2007.

CANOTILHO, José Joaquim Gomes. Constituição Dirigente e Vinculação do Legislador: Contributo para a Compreensão das Normas Constitucionais Programáticas. 2. ed., Coimbra: Coimbra Editora, 2001. 
CANOTILHO, J.J. Gomes; MENDES, Gilmar Ferreira; SARLET, Ingo Wolfgang. STRECK, Lenio Luiz. (Coords.). Comentários à Constituição do Brasil. São Paulo: Saraiva/Almedina, 2013.

CRISAFULLI, Vezio. La Costituzione e le sue disposizioni di principio. Milano: Giuffrè, 1952.

COPETTI NETO, Alfredo. A democracia constitucional sob o olhar do garantismo jurídico. No prelo.

COPETTI NETO, Alfredo. Pragmatismo em Filosofia, Realismo em Direito e o Duplo Assalto à Economia Política Clássica: as bases do First Law and Economics Movement na Progressive Era Americana (1880-1930). In: Seqüência. UFSC, Florianópolis, SC, Brasil, ISSNe 2177-7055, 2012.

COPETTI NETO, Alfredo. Uma perspectiva garantista do liberalismo e da democracia: marcos históricos e possibilidades contemporâneas edificados a partir de Principia iuris. In:VIANNA, Túlio; MACHADO, Felipe (coords). Garantismo Penal no Brasil: Estudos em Homenagem a Luigi Ferrajoli.Belo Horizonte: Fórum, 2013a.

COPETTI NETO, Alfredo; CATTONI DE OLIVEIRA, Marcelo. Entre direito, economia e política - as contribuições da ciência do estado alemã (Staatswissenchaft) para o surgimento no século XIX de uma nova ciência do direito. In: Revista Novos Estudos Jurídicos. Vol 18. n.1, $2013 b$.

GRAU, Eros Roberto. A ordem econômica na Constituição de 1988. 13.ed. São Paulo: Malheiros, 2008.

FERRAJOLI, Luigi. Direito e razão: teoria do garantismo penali. São Paulo: Editora Revista dos Tribunais, 2002.

FERRAJOLI, Luigi. Principia iuris I: teoria del diritto. Roma-Bari: Laterza, 2007.

FERRAJOLI, Luigi. Principia iuris II: teoria della democracia. Roma-Bari: Laterza, 2007.

FERRAJOLI, Luigi. La democrazia attraverso i diritti. Roma: Laterza, 2013.

FERREIRA FILHO, Manoel Gonçalves. Constituição e Governabilidade: Ensaio sobre a (In)Governabilidade Brasileira. São Paulo: Saraiva, 1995.

GREEN, Thomas H. Lectures on the principles of political obligation (P. Harris \& J. Morrow, Eds.). Cambridge: Cambridge University Press, 1986.

HESSE, Konrad. A força normativa da constituição. Porto Alegre: SAFE, 1991.

HOBHOUSE, Leonard. Liberalism. London: Oxford University Press, 2009.

LASSALLE, Ferdinand. Que é uma Constituição? São Paulo: Edições e publicações Brasil, 1933. 
MERQUIOR, José Guilherme. O liberalismo Antigo e Moderno. Rio de Janeiro: Editora Nova Fronteira, 1991.

MILL, Stuart. Sobre la Libertad. Trad. Josefa Sainz Pulido. $3^{\mathrm{a}}$ ed. Aguilar Editor: Buenos Aires, 1962.

MOREIRA, Vital. Economia e constituição. Coimbra: Almedina, 2002.

MYDRAL, Gunnar. Beyond the Welfare State. London: Duckwth. 1960.

SARLET, Ingo W. Comentário ao artigo $1^{\circ}$, III. In: CANOTILHO, J.J. Gomes; MENDES, Gilmar Ferreira; SARLET, Ingo Wolfgang. STRECK, Lenio Luiz. (Coords.) Comentários à Constituição do Brasil. São Paulo: Saraiva/Almedina, 2013.

SARLET, Ingo Wolfgang. Os Direitos Fundamentais Sociais na Constituição Federal de 1988: resistências à sua eficácia e efetividade.. In: VIEIRA, José Ribas. (Org.). 20 Anos da Constituição Cidadã de 1988: efetivação ou impasse institucional?. Rio de Janeiro: Forense, 2008, v. 1, p. 291-318.

SEN, Amartya K. La democrazia degli altri: perchè la liberta non è una invenzione dell'occidente. Milano: Mondadori, 2005.

SEN, Amartya K. Scelta, benessere, equità. Bologna: Mulino, 2006.

SILVA, José Afonso da.A aplicabilidade das normas constitucionais. São Paulo: Malheiros, 1999.

STRECK, Lenio Luiz; BOLZAN de MORAIS, José Luis. Comentário ao artigo $1^{\circ}$, caput. In: CANOTILHO, J.J. Gomes; MENDES, Gilmar Ferreira; SARLET, Ingo Wolfgang. STRECK, Lenio Luiz. (Coords.) Comentários à Constituição do Brasil. São Paulo: Saraiva/Almedina, 2013.

VENANCIO FILHO, Alberto. A intervenção do Estado no Domínio Econômico. Rio de Janeiro: FGV, 1968. 